\title{
REFERENCES
}

1. B. LoVReČex, A. DespiĆ and J. O'M. BockRIs, J. phys. Chem. 63, 750 (1959).

2. V. N. MAsLov and A. V. Ovodova, Zh. fiz. Khim. 34, 413 (1960).

3. B. LoVReČCER and B. KuNst, Nature, Lond. 189, 804 (1961).

4. B. Lovré̌kz and B. KuNsT, Croat. chem. Acta 34, 137, 219 (1962).

5. H. Z. FriedLinder, J. Polym. Sci. C4, 1447 (1963).

6. A. MAURo, Biophys. J. 2, 179 (1962).

7. P. LÄuger, Ber. Bunsenges. 68, 534 (1964).

8. M. SENo and T. YAMABE, Bull. chem. Soc. Japan 37, 668 (1964).

9. M. SCHWARTZ and C. T. CAsE, Biophys. J. 4, 137 (1964).

10. S. OHRI, J. phys. Soc. Japan 20,1674 (1965).

11. H. G. L. Coster, Biophys. J. 5, 669 (1965).

Electrochimica Acta, 1967, Vol. 12, pp. 907 to 909. Pergamon Press Ltd. Printed in Northern Ireland

\section{SOME PROPERTIES OF SOLUTIONS OF HYDROGEN CHLORIDE IN DIMETHYLSULPHOXIDE*}

\author{
J. A. Olabe, M. C. Gtordano and A. J. Arvfa \\ Instituto Superior de Investigaciones, Facultad de Qulmica y Farmacia, \\ Universidad Nacional de La Plata, La Plata, Argentina
}

As PART of a research on the electrochemistry of solutions of inorganic compounds in dimethylsulphoxide (DMSO), ${ }^{1,2}$ solutions of hydrogen chloride in this solvent were investigated. These solutions were prepared at different concentrations in an all-glass apparatus, by dissolving anhydrous hydrogen chloride in highly purified DMSO previously cooled down to about $0^{\circ} \mathrm{C} .^{3}$

When it was attempted to prepare solutions of a concentration higher than $4 \mathrm{M}$, the formation of a colourless, crystalline solid was observed. After separating the latter from the solution, its chemical analysis gave the following minimum formula: DMSO. $\mathrm{HCl}$ ( $\mathrm{HCl}$ found: 30.2 per cent; theoretical: 31.9 per cent). The difference is reasonable because the solid decomposes easily when it is put in contact with air, so that it becomes difficult to make a complete drying of the sample. For the same reason the melting point was not determined.

The ir spectrum of solutions of increasing concentration of $\mathrm{HCl}$ in DMSO shows a strong wide band in the region between 3000 and $3500 \mathrm{~cm}^{-1}$, in the place where the $\mathrm{O}-\mathrm{H}$ absorption band may be expected. ${ }^{4,5}$ A shift of the $\mathrm{S}-\mathrm{O}$ stretching frequency towards lower values has been observed, as well as an increase of the C-S stretching frequency as compared to the pure solvent. This indicates that the hydrogen is probably bound to a solvent molecule just as in the case of solutions of perchloric acid in DMSO. ${ }^{\circ}$

Preliminary data about the electrical conductivity and the viscosity of solutions

* Manuscript received 2 January 1967. 
at different concentrations are reported in Table 1. No time effect was observed in the conductivity measurements.?

The molar-conductivities are lower than those to be expected from a completely dissociated 1-1 type electrolyte, as in aqueous hydrochloric acid solutions. ${ }^{8}$ The apparent limiting molar conductance does not fit Walden's rule, as was found for other 1-1 type electrolytes in DMSO.9

TABLE 1

\begin{tabular}{|c|c|c|}
\hline $\begin{array}{l}\mathbf{C} \\
\mathbf{M}\end{array}$ & $\underset{\mathrm{cm} / \Omega}{\Lambda_{c}}$ & $\begin{array}{c}\eta \times 10^{2} \\
\mathrm{~g} / \mathrm{s} \mathrm{cm}\end{array}$ \\
\hline 0.0004 & $57 \cdot 1$ & $2 \cdot 242$ \\
\hline 0.0008 & $46 \cdot 3$ & $2 \cdot 247$ \\
\hline 0.0017 & 40.9 & $2 \cdot 248$ \\
\hline 0.0038 & $34 \cdot 3$ & $2 \cdot 247$ \\
\hline 0.0070 & 29.8 & $2 \cdot 303$ \\
\hline 0.0155 & $23 \cdot 3$ & $2 \cdot 364$ \\
\hline 0.1712 & $10 \cdot 1$ & $2 \cdot 422$ \\
\hline 0.9766 & $4 \cdot 7$ & $2 \cdot 627$ \\
\hline $2 \cdot 149$ & $3 \cdot 1$ & $4 \cdot 106$ \\
\hline 3.377 & $2 \cdot 1$ & $6 \cdot 718$ \\
\hline
\end{tabular}

The transference number for the cation, as determined by Hittorf's method, was about 0.3 at $25^{\circ} \mathrm{C}$. This shows that the cation has a lower mobility than that deduced from hydrogen ion in aqueous solution, at the same concentration.

The above mentioned properties suggest that the interaction between hydrogen chloride and DMSO comprises the initial formation of a molecular complex, according to

$$
\mathrm{DMSO}+\mathrm{HCl} \rightleftharpoons \mathrm{DMSO} . \mathrm{HCl}
$$

This complex should involve at least two structures, already reported for other DMSO complexes, ${ }^{10}$

$$
\text { DMSO.HCl } \rightleftharpoons \mathrm{DMSOH}^{+} . \mathrm{Cl}^{-}
$$

and in the presence of an excess of solvent,

$$
\mathrm{DMSOH}^{+} \cdot \mathrm{Cl}^{-} \rightleftharpoons \mathrm{DMSOH}^{+}+\mathrm{Cl}^{-},
$$

the ions being in part responsible for the properties of the solutions observed.

The electrolysis of hydrogen chloride solutions in DMSO at room temperature on platinum electrodes produces hydrogen gas on the cathode with nearly a 100 per cent yield. No gas evolution occurs in the anode, but a yellow-tinged solution is left after a long time of electrolysis. It is likely that the discharge of chloride ions leads to the formation of chlorine atoms on the electrode surface, and these subsequently react with the solvent. Products of the anodic reaction are not yet identified. A complete electrochemical study will be published in the near future.

Acknowledgement-This work was done in part with financial aid of the Consejo Nacional de Investigaciones Cientificas y Técnicas of Argentina. J. A. O. thanks the Facultad de Ciencias Fisicomatematicas de la Universidad de La Plata for the scholarship granted. 


\section{REFERENCES}

1. M. C. Giordano, J. C. Bazán and A. J. Arvía, Electrochim. Acta 11, 741 (1966).

2. M. C. Giordano, J. C. BazAN and A. J. ARviA, Electrochim. Acta 11, 1553 (1966).

3. I. M. Kolthofr and T. B. REDDY, J. electrochem. Soc. 108, 980 (1961).

4. P. Barnard, J. N. Fablan and H. P. Kock, J. chem. Soc. 2442 (1949).

5. K. NAKAMOTo, Infrared Spectra of Inorganic and Coordination Compounds p. 81. Wiley, New York (1963).

6. G. J. JANZ and S. S. DanYuUK, in Electrolytes, ed. B. Pesce, p. 255. Pergamon, Oxford (1962).

7. D. C. Wimer, Analyt. Chem. 30, 2060 (1958).

8. H. S. HARNED and B. B. OWEN, The Physical Chemistry of Electrolytic Solutions, Chap. 11. Reinhold, New York (1958).

9. J. A. Bolzan, M. C. Grordano and A. J. Arvía An. Asoc. quim. Argent. 54, 171 (1966).

10. M. C. Grordano, J. C. Bazán and A. J. Arvía, J. inorg. nucl. Chem. 28, 1209 (1966). 